\title{
Climate Change Promotes the Emergence of Serious Disease Outbreaks of Filarioid Nematodes
}

\author{
Sauli Laaksonen, ${ }^{1}$ Jyrki Pusenius, ${ }^{2}$ Jouko Kumpula, ${ }^{3}$ Ari Venäläinen, ${ }^{4}$ Raine Kortet, ${ }^{5}$ \\ Antti Oksanen, ${ }^{1}$ and Eric Hoberg ${ }^{6}$ \\ ${ }^{1}$ Finnish Food Safety Authority Evira (FINPAR), P.O. Box 517, FI-90101 Oulu, Finland \\ ${ }^{2}$ Finnish Game and Fisheries Research Institute, FI-80100 Joensuu, Finland \\ ${ }^{3}$ Finnish Game and Fisheries Research Institute, FI-99910 Kaamanen, Finland \\ ${ }^{4}$ Finnish Meteorological Institute, P.O. Box 503, FI-00101 Helsinki, Finland \\ ${ }^{5}$ Department of Biology, University of Eastern Finland, P.O. Box 111, FI-80101 Joensuu, Finland \\ ${ }^{6}$ US National Parasite Collection, ARS, USDA, Animal Parasitic Diseases Laboratory, BARC East 1180, 10300 Baltimore Avenue, Beltsville, MD 20705
}

\begin{abstract}
Filarioid parasites represent major health hazards with important medical, veterinary, and economic implications, and considerable potential to affect the everyday lives of tens of millions of people globally (World Health Organization, 2007). Scenarios for climate change vary latitudinally and regionally and involve direct and indirect linkages for increasing temperature and the dissemination, amplification, and invasiveness of vector-borne parasites. High latitude regions are especially influenced by global climate change and thus may be prone to altered associations and dynamics for complex host-pathogen assemblages and emergence of disease with cascading effects on ecosystem structure. Although the potential for substantial ecological perturbation has been identified, few empirical observations have emanated from systems across the Holarctic. Coincidental with decades of warming, and anomalies of high temperature and humidity in the sub-Arctic region of Fennoscandia, the mosquito-borne filarioid nematode Setaria tundra is now associated with emerging epidemic disease resulting in substantial morbidity and mortality for reindeer and moose. We describe a hostparasite system that involves reindeer, arthropods, and nematodes, which may contribute as a factor to ongoing declines documented for this ungulate species across northern ecosystems. We demonstrate that mean summer temperatures exceeding $14^{\circ} \mathrm{C}$ drive the emergence of disease due to $S$. tundra. An association between climate and emergence of filarioid parasites is a challenge to ecosystem services with direct effects on public health, sustainability of free-ranging and domestic ungulates, and ultimately food security for subsistence cultures at high latitudes.
\end{abstract}

Keywords: global warming, filarioid nematodes, vector-borne diseases, emerging diseases, reindeer populations, sub-Arctic

\section{INTRODUCTION}

Published online: April 27, 2010

Correspondence to: Sauli Laaksonen, e-mail: sauli.laaksonen@evira.fi
Setaria tundra, a species of filarioid nematode, has caused three documented disease outbreaks among cervids in 
Finland, including those in reindeer (Rangifer tarandus) in 1973 and 2003-2005 (Laaksonen et al., 2007) and in moose (Alces alces) in 1989 (Nygren, 1990). The first recognized outbreak of $S$. tundra in Fennoscandia was reported by Rehbinder et al. (1975) in 1972-1973 among Swedish reindeer originating from forest herds at relatively low altitudes; in contrast, the parasite was apparently absent in animals from mountain herds. In 1973, S. tundra was associated with "rather" poor body condition and peritonitis. Later, in the winter of 1973-1974, tens of thousands of reindeer died in the northern part of Finnish reindeer herding area, where severe peritonitis and large numbers of Setaria sp. worms were commonly found in postmortem examination (see Laaksonen et al., 2007). During this outbreak, the Finnish reindeer population decreased from 140,000 to 98,000 . The reduction was most intense in the northern (Sodankylä level; Fig. 1) and eastern (Kuusamo) areas where the population decreased by 40 and $30 \%$, respectively (Database of Finnish Reindeer Herders' Association). Further in 1973-1974, S. tundra was observed for the first time in Norway where an explosive epidemic among northern herds resulted in widespread condemna-

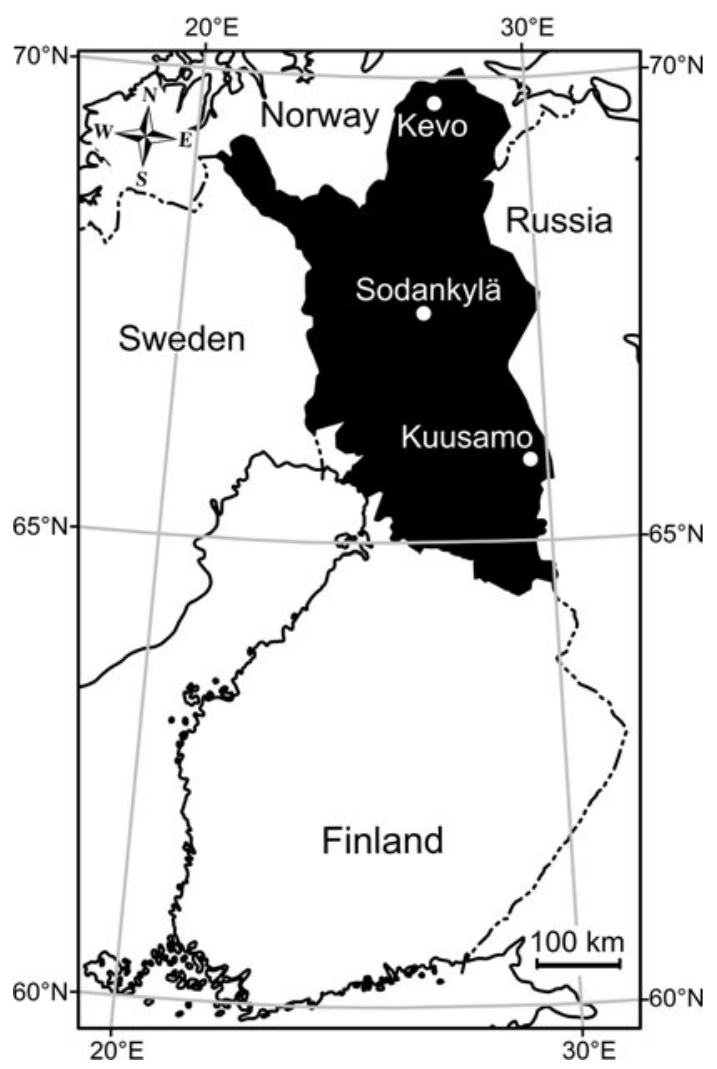

Figure 1. Distribution of herding areas for Finnish reindeer (black) and the location of the three weather stations representing the region. tion of meat, livers, and adjacent tissues due to the effects of peritonitis, hepatitis, and perihepatitis (Kummeneje, 1980). The most recent epidemic in reindeer rapidly emerged in 2003 across the southern parts of the Finnish reindeer herding area and was first noticed in the Kuusamo region. As of 2005, expansion of the outbreak was extensive, and only the reindeer in the northernmost part of Finland (Kevo area) appeared to remain free of disease, although carriers of $S$. tundra also appeared in northern herds (Laaksonen et al., 2008a).

An outbreak of Setaria sp. (later determined to be $S$. tundra (Laaksonen et al., 2008a)) in Finnish moose was reported in 1989 by Nygren (1990) based on an extensive examination of the genital tracts and adjacent tissues from 1,132 females originating from the Finnish reindeer herding area. The number of moose examined in this study represented $83 \%$ of hunted females in the area. Setaria sp. or a marked inflammatory granulomatous reaction associated with the parasite was recorded in $29 \%$ of the adult hinds, whereas $46 \%$ of calves and $55 \%$ of yearlings were infected. The epidemic was most intense in the southern and middle parts of the reindeer herding area, whereas moose from the northern part appeared free of infection. Although this outbreak took place within the core of the reindeer husbandry area, and the reindeer population was in its peak (Database of Finnish Reindeer Herders' Association), no meat inspection reports indicate increased morbidity associated with Setaria in reindeer.

Setaria tundra nematodes have a complex life cycle where infective larvae are transmitted to ungulate hosts by mosquitoes (Culicidae) and in which many climate-related drivers play a major role (Laaksonen et al., 2009). Massive swarms of blood-feeding insects attacking herds of caribou/ reindeer are well known (Anderson and Nilssen, 1998). Some estimates suggest that reindeer can be exposed to attacks of approximately 8,000 mosquitoes per hour during the mass appearance of blood sucking insects (Kadnikov, 1989), which locally is known as a "räkkä" (see Laaksonen et al., 2009). Prevalence of S. tundra among different mosquito populations in 2004 across endemic regions in Finland was $0.5-2.5 \%$ (Laaksonen et al., 2009). In these conditions, reindeer could hourly be attacked by 40 to 200 mosquitoes carrying infective larvae of S. tundra. Habitat preferences by reindeer during periods of high temperatures during the summer also may contribute as a determinant of exposure to infection. During the height of warm summers, hundreds of reindeer congregate in dense herds in low elevation, mosquito-rich wetlands coinciding with 
areas of considerable activity by vectors (Laaksonen et al., 2009). In these areas the microclimate is favorable for mosquitoes, and it is presumed that hyperendemic foci of infection enhance the potential for transmission; for example, in these wetland habitats, the infection rate of $S$. tundra in mosquitoes can reach and occasionally exceed $2.5 \%$ (Laaksonen et al., 2009). Vector breeding sites are not limited by humidity or water resources, because mires and bogs constitute approximately $30-40 \%$ of the total land area in the regions where outbreaks of $S$. tundra have been recognized. In contrast, only approximately $12 \%$ of upper Lapland is bog habitat (Kumpula et al., 1999), which may restrict transmission (Laaksonen et al., 2007, 2008a).

Where favorable environmental and host factors coincide, the transmission of $S$. tundra is highly dependent on the life span of female mosquitoes and the specific demographics of the population (Laaksonen et al., 2009); survival of adult mosquitoes is in part dependent on both temperature and humidity (Barry and Juliano, 2001). For example, during the latest epidemic, older females comprised a considerable component of the "wild" mosquito population but densities were low (Laaksonen et al., 2009). In contrast, the $S$. tundra outbreak in Sweden in 1973 was associated with unusually warm weather and with the appearance of especially large numbers of mosquitoes (Rehbinder et al., 1975). The presence and proportion of older female mosquitoes in a given population, however, is a more critical factor for transmission of $S$. tundra rather than the density alone. Older females may have fed several times and are thus more likely to have become infected with tens of $S$. tundra larvae (Laaksonen et al., 2009). Within limits, warmth also affects the development, reproduction, longevity, and feeding habits of mosquito vectors (Clements, 1963, Delatte et al., 2009), and the lowest temperature of the seasonal regime is a limiting factor for survival (e.g., in Aedes albopictus) (LöwenbergNeto and Navarro-Silva, 2004). Furthermore, the hematophagic activities and oviposition of mosquitoes, for example Ae. albopictus, may be significantly influenced by temperature (Calado and Navarro-Silva, 2002). Finally, the development of $S$. tundra to the infective stage in mosquitoes is highly temperature-dependent and inversely related. Warmth decreases the time required for the larval development of S. tundra (Laaksonen et al., 2009). It is obvious that these factors of the biology of hosts (both definitive host and arthropod vectors) and parasites may act in synergy with the environmental conditions to en- hance the potential for significant transmission, infection, and disease outbreaks (Lafferty, 2009; Gubler et al., 2001).

Mosquito-borne pathogens and diseases are predicted to be among the most climate-sensitive maladies (Patz et al., 1996); however, to date, little empirical evidence has been presented. Hoberg et al. (2008a, b) discussed some interactions among these drivers related to climate, and the present study provides strong empirical evidence of the relationship. The outbreaks in 1973 and 2003-2005 led to substantial losses to the herding economy and had a pronounced influence on the welfare of calves (Laaksonen et al., 2007, 2008b). The outbreaks have revealed that $S$. tundra can act as a significant pathogen for reindeer, which was evident at both ante- and postmortem inspection of slaughter animals and in histological and experimental examinations (Laaksonen et al., 2007, 2008b). Thus, these parasites represent a considerable threat to biological diversity, ecological continuity, and cultural and socioeconomic well-being in the region.

\section{Methods}

We studied the effects of ambient summer temperatures on the known outbreaks of $S$. tundra in populations of Finnish cervids, based on historical weather data (19612004) from three independent meteorological stations of the Finnish Meteorological Institute representing the reindeer herding area of Finland (Kuusamo, Sodankylä and Kevo) (Fig. 1). The weather stations are the only ones in the study area. Kuusamo and Sodankylä represent the outbreak areas in 1989 and 2003-2005, whereas all the stations represent the outbreak area in 1973. We tested a hypothesis that the probability of Setaria outbreak in year $t$ depends on the summer mean temperatures (summer period: June-August) during year $t$ and year $t-1$. We also assessed whether a high current year summer temperature, $T t$, was sufficient for an epidemic or whether the effect of current year temperature depended on summer temperature during year $t-1$. To do this, we fitted a generalized linear mixed model with binomial errors into the data. The occurrence of an epidemic was a dichotomous dependent variable; mean summer temperatures $T t, T t-1$, and their interaction, as well as site (a random effect) were independent variables in the model. The analysis was performed using PROC GENMOD (SAS Institute). 


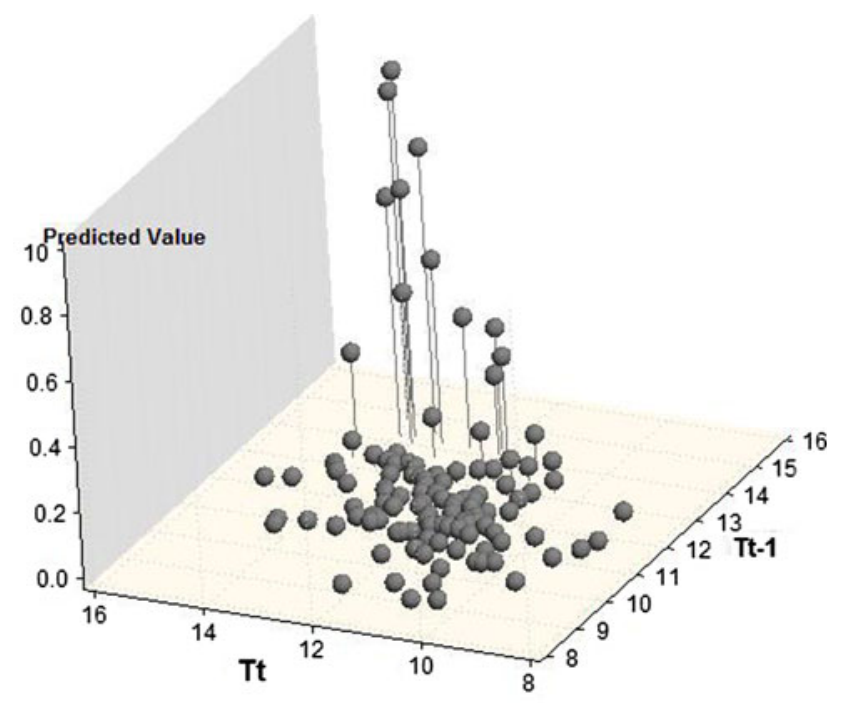

Figure 2. Predicted probabilities of Setaria tundra outbreaks as a function of mean summer temperature, $T t$ and $T t-1\left({ }^{\circ} \mathrm{C}\right)$, for an outbreak and the preceding year. The predictions were obtained from a generalized linear model (occurrence of epidemic regressed against $T t, T t-1$ and their interaction).

\section{Results}

The results of generalized linear modelling indicated that the occurrence of an epidemic increased with $T t$ ( $b=6.60 \pm 3.39$ (s.e.); $P=0.0004)$. However, this effect was conditional on $T t-1$ since a significant $T t \times T t-1$ interaction was also observed $(b=-0.86 \pm 0.23$, $P=0.0002)$. On the basis of our model, high $T t$ was likely to cause an epidemic only if $T t-1$ was higher than $14^{\circ} \mathrm{C}$ (Fig. 2). The mean summer temperature for the region in study period was $12^{\circ} \mathrm{C}$ (range, 8.8-15.1).

\section{Discussion}

Our data obtained in this study suggest that warm episodes or otherwise extreme events of temperature, embedded within long-term trends for climate warming, are a factor that promotes serious outbreaks and emergence of $S$. tundra. These factors may represent a generalized determinant for occurrence and outbreaks for other filarioid parasites across northern latitudes.

There are many nonclimatological and climatological factors that enhance the life cycle of $S$. tundra, its transmission, and survival in the reindeer population. Many of these factors remain linked to climate at some level. The effect of these drivers on the patterns of distribution for parasites in both definitive hosts and vectors, overall hostpathogen relationships and emergence of an outbreak, may be both incremental (cumulative) and extreme (episodic). The synchrony between peak periods of S. tundra microfilaremia, peak activity of vectors, shedding of adult reindeer, and low immunity status of calves (Laaksonen et al., 2008a, b, 2009) probably promotes the transmission of $S$. tundra from adult carriers to calves. Contributing factors in determining patterns of transmission and outbreaks are seen in the high capacity of $S$. tundra to produce microfilariae (Nikander et al., 2007), high vector efficiency (Laaksonen et al., 2009), the stress and host behavior during warm periods (Helle and Aspi, 1984; Helle et al., 1992; Pollard et al. 1996; Mörchel and Klein, 1997; Anderson and Nilssen, 1998; Weladj et al., 2002; Laaksonen et al., 2009), and the impact on host physiology (Laaksonen et al., 2008a) of insect harassment. The observations also suggest that the migrations of reindeer (Laaksonen et al., 2009) and the characteristics of reindeer pastures (Rehbinder et al., 1975; Dadaev, 1984; Laaksonen et al., 2009) are involved. On the population level, the abundance of sylvatic reservoirs (Laaksonen et al., 2007, 2008a, b), the host density (Laaksonen et al., 2008b), and massive antiparasitic treatment in semidomesticated reindeer (Laaksonen et al., 2008b), as well as growing immunity in host populations may interact (Laaksonen et al., 2008a).

The possibility for emergence of the outbreaks being linked to the introduction of a new $S$. tundra strain that could have been more pathogenic for hosts cannot be excluded (Nikander et al., 2007; Laaksonen et al., 2008a; Hoberg, 2010). Interestingly, molecular sequence data indicate that discrete populations of $S$. tundra may be circulating in moose and reindeer, respectively, even in zones of sympatry (Laaksonen et al., 2008a, b). During the recent epidemic in reindeer during 2003-2005, the moose population peaked in northern Finland and no cases of acute peritonitis or living adult $S$. tundra worms were detected; only a few preadults were found encapsulated on the surface of livers (Laaksonen et al., 2007). Thus, parasites circulating in reindeer and roe deer, demonstrated as the causative agent of the 2003-2005 outbreak, appear to be discrete from those that may be circulating in moose or other cervids (Laaksonen et al., 2007, 2008a). Parasite species diversity and population structure for Setaria are factors that require further exploration in determining relationships to past and future outbreaks.

The results obtained from model-development in the current study are congruent with the observations made 


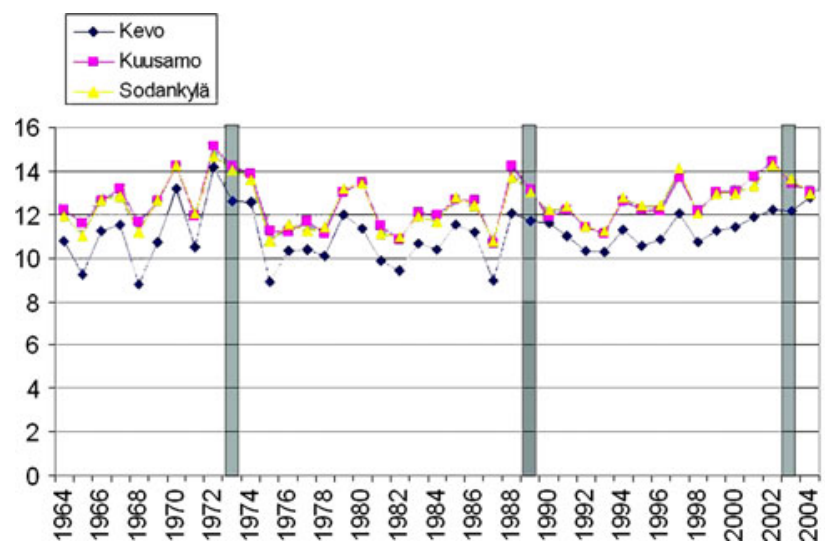

Figure 3. Variation in mean summer temperatures (lines) in Finnish Lapland with the known outbreaks of Setaria tundra in reindeer (1973 and 2003) and moose (1989) indicated (bars). Annual mean summer temperatures were recorded at three observation stations: Kevo, Kuusamo, and Sodankylä (Fig. 1).

during the origin of the recent disease outbreak (Laaksonen et al., 2007, 2008a). Emergence of disease conditions is not immediate and is associated with considerable lag time between initial transmission, infection, and development of adult parasites in the mammalian host. Summer temperatures greater than $14^{\circ} \mathrm{C}$ increase infection rates, but the morbidity manifests the following summer only if the weather conditions are still favorable. According to meat inspection data, the prevalence of $S$. tundra infection had already increased in slaughter-reindeer in 2002, one year before the outbreak (Laaksonen et al., 2007), and the degree of disease was correlated with the intensity of infection (Laaksonen et al., 2007). It is therefore reasonable to assume that the parasite must reach prevalence high enough in the population before the other conditions enabling the outbreak surpass a threshold. Such a relationship is clearly demonstrated empirically by the interaction between cumulative long-term trends in temperature, mean summer temperatures exceeding $14^{\circ} \mathrm{C}$, and by the fact that outbreak years with the subsequent emergence of diseases in cervids have been warm (mean $13.4^{\circ} \mathrm{C}$; range 12.6-14.2; Fig. 3). In this system, temperature increases greater than $14^{\circ} \mathrm{C}$ may represent a tipping point for development and amplification of parasite populations (Hoberg et al., 2008a). These interacting cumulative factors provide an explanation for the temporal duration over 2 years (Kummeneje, 1980; Rehbinder et al., 1975; Laaksonen et al., 2007) and geographic extent of emergent disease. In this regard, the outbreak reached upper Lapland (Kevo, the region of greatest reindeer density) in 1973 when temperatures were elevated in 1972, but not in 2003-2005 after the summer of 2002 when the summer temperature did not exceed $14^{\circ} \mathrm{C}$ (Laaksonen et al., 2007, 2008a). As evidence of this cumulative interaction, the documented genesis of the epidemic in 2003 occurred in the area where the host density is lowest and subsequently spread into adjacent areas (Sodankylä) in 2004 and 2005 (Tt 12.9 and $14.3^{\circ} \mathrm{C}$, respectively (Database of Finnish Meteorological Institute) where reindeer were considerably more abundant (Laaksonen et al., 2008b).

The Arctic climate is under accelerating change resulting in both incremental (cumulative) warming and extreme (episodic) weather events that influence temperature and hydrological processes (Patz et al., 1996). Such processes serve as the physical drivers for changing dynamics in patterns of distribution (host and geographic), development, survival, and transmission for an array of pathogens (Kutz et al., 2004, 2005; Hoberg et al., 2008a). Cascading and cumulative effects of climate change include shifts in hostpathogen relationships. Thus, in the future in many areas, conditions for a diverse assemblage of disease vectors and intermediate hosts of parasites will likely improve leading to a modification in the intricate balance that determines the distribution for emergent disease (Dobson and Foufopoulus, 2001; Hoberg et al., 2008a). For example, in certain latitudinal zones, coincidental with melting permafrost and increasing rainfall, the area and number of suitable habitats for mosquitoes may expand. Pathogen transmission and patterns of emerging disease may become further altered through spatial and temporal shifts in geographic range, patterns of reproduction, and longevity for vectors (Patz et al., 2000; Hoberg et al., 2008b). Higher temperatures also may increase the biting rates for vectors and shorten the incubation period for pathogens (Patz et al., 2000) and alter the behavior of hosts (Laaksonen et al., 2009). Factors associated with the life history of both arthropod intermediate and ungulate definitive hosts can be convergent in amplification of parasite populations. For example, in the study area during periods of high temperatures, dense herds of reindeer aggregated in the mosquito-rich wetlands in response to available water, abundant forage, and habitat-related thermoregulation (Laaksonen et al., 2009). Alternatively, accelerated climate change may have the potential for negative or neutral effects, and not all environmental perturbation will lead to emergence, particularly where tolerances and resilience of developmental stages for parasites and vectors are exceeded by ambient conditions (Lafferty, 2009; Gubler et al., 2001). 


\section{CONCLUSIONS}

Climate and associated weather events are increasingly being recognized or predicted as factors linked to emerging diseases attributable to both helminth macroparasites and microparasites, including bacterial pathogens (Handeland and Slettbakk, 1994; Patz et al., 1996; Harvell et al., 2002; Kutz et al., 2005; Jenkins et al., 2006; Hoberg et al., 2008a; Ytrehus et al., 2008; Laaksonen et al., 2009) in these high-latitude systems. Drivers for emergence are predicted to be complex, and for S. tundra represent interactions among mammals, arthropods, and parasites where both direct and indirect effects of temperature and humidity can influence the outcome. Causes of the current and expanding declines in global populations of caribou and reindeer remain poorly understood, but parasites and pathogens have not been considered in synergy with a diverse array of abiotic and biotic determinants (Vors and Boyce, 2009; Kutz et al., 2009a). Conditions in the sub-Arctic region of Fennoscandia clearly indicate the potential impact of pathogens on the viability, persistence, and sustainability of populations of semidomestic and free-ranging ungulates (Laaksonen et al., 2007). Environmental perturbation and emergent disease can threaten food security, socioeconomic and ecological stability across the north with pervasive cascading effects for northern cultures, and communities that remain dependant on wildlife resources (Hoberg et al., 2008a, b). Consequently, parasites, pathogens and disease must be factored into the equations for understanding current and future scenarios for high-latitude ecosystems under a regime of accelerating change (Kutz et al., 2004, 2009b; Lemke et al., 2007; Hoberg et al., 2008a, b; Tryland et al., 2009).

Beyond the sub-Arctic, a future of global climate change could facilitate translocation, geographic expansion, and dissemination of pathogenic tropical filarioids into the Northern Hemisphere, leading to detrimental effects on mammalian host populations and expansion of zoonotic infections in humans (Taylor et al., 2001). Understanding these processes depends on broadened investigations and surveillance exploring the emergence of vector-borne and other parasitic diseases in northern wildlife, with attention to the complex interactions among parasites, their invertebrate and mammalian hosts, and the environment (Kuiken et al., 2005). Ecosystem approaches that develop comprehensive baselines for biodiversity (linked to museum archives) against which to assess environmental change and an exploration of developmental thresholds, tolerance, and resilience for pathogens and hosts are requisite components of such programs (Hoberg et al., 2008a, b; Tryland et al., 2009).

\section{OPEn ACCESS}

This article is distributed under the terms of the Creative Commons Attribution Noncommercial License which permits any noncommercial use, distribution, and reproduction in any medium, provided the original author(s) and source are credited.

\section{REFERENCES}

Anderson JR, Nilssen A (1998) Do reindeer aggregate on snow patches to reduce harassment by parasitic flies or thermoregulate? Rangifer 18:3-17

Barry WA, Juliano SA (2001) Precipitation and temperature effects on populations of Aedes albopictus (Diptera: Culicidae): implications for range expansion. Journal of Medical Entomology 38:646-656

Calado DC, Navarro-Silva MA (2002) Influência da temperatura sobre a longevidade, fecundidade e atividade hematofágica de Aedes (Stegomyia) albopictus Skuse, 1894 (Diptera, Culicidae) sob condições de laboratório [in Portuguese with English abstract]. Revista Brasileira de Zoologia 46:93-98

Clements AN (1963) The Physiology of Mosquitoes, Oxford: Pergamon Press

Dadaev S (1984) Special features of the prevalence of the nematode Setaria labiatopapillosa in cattle in Uzbekistan. Uzbekskii Biologicheskii Zhurnal 4:40-42

Delatte H, Gimonneau G, Triboire A, Fontenille D (2009) Influence of temperature on immature development, survival, longevity, fecundity, and gonotrophic cycles of Aedes albopictus, vector of Chikungunya and Dengue in the Indian Ocean. Journal of Medical Entomology 46:33-41

Dobson AP, Foufopoulus J (2001) Emerging infectious pathogens of wildlife. Philosophical Transactions of the Royal Society $B$ 356:1001-1012

Gubler DJ, Reiter P, Ebi KL, Yap W, Nasci R, Patz JQA (2001) Climate variability and change in the United States: potential impacts on vector- and rodent-borne disease. Environmental Health Perspectives 109:223-233

Handeland K, Slettbakk T (1994) Outbreaks of clinical cerebrospinal elaphostrongylosis in reindeer (Rangifer tarandus taran$d u s)$ in Finnmark, Norway, and their relation to climatic conditions. Journal of Veterinary Medicine Series B 41:407-410

Harvell CD, Mitchell CE, Ward JR, Altizer S, Dobson AP, Ostfeld RS, et al. (2002) Climate warming and disease risks for terrestrial and marine biota. Science 296:2158-2162. doi:10.1126/ science.1063699

Helle T, Aspi J (1984) Do sandy batches help reindeer against insects? Reports from the Kevo Subarctic Research Station 19:57-62

Helle T, Aspi J, Lempa K, Taskinen E (1992) Strategies to avoid biting flies by reindeer: field experiment with silhouette traps. Annales Zoologici Fennici 29:69-74 
Hoberg EP (2010) Invasive processes, mosaics and the structure of helminth parasite faunas. Scientific and Technical Review International Office of Epizootics 29 (in press)

Hoberg EP, Polley L, Jenkins EJ, Kutz SJ, Veitch AM, Elkin BT (2008a) Integrated approaches and empirical models for investigations of parasitic diseases in northern wildlife. Emerging Infectious Diseases 14:10-17

Hoberg EP, Polley L, Jenkins EJ, Kutz SJ (2008b) Pathogens of domestic and free-ranging ungulates: global climate change in temperate to boreal latitudes across North America. Revue Scientifique et technique (International Office of Epizootics) 27:511528. doi:10.3201/eid1401.071119

Jenkins EJ, Veitch AM, Kutz SJ, Hoberg EP, Polley L (2006) Climate change and the epidemiology of protostrongylid nematodes in northern ecosystems: Parelaphostrongylus odocoilei and Protostrongylus stilesi in Dall's sheep (Ovis d. dalli). Parasitology 132:387-401. doi:10.1017/S0031182005009145 [online December 7, 2005]

Kadnikov VV (1989) Protecting reindeer from insects as a way of preventing necrobacillosis [in Russian]. Veterinariya (Moscow) 8:26-27

Kuiken T, Leighton FA, Fouchier RAM, LeDuc JW, Peiris JSM, Schudel A, et al. (2005) Pathogen surveillance in animals. Science 309:1680-1681. doi:10.1126/science. 1113310

Kummeneje K (1980) Diseases in reindeer in northern Norway. In: Proceedings of the Symposium of the Second International Reindeer-Caribou Symposium on Roros 17-21 September Part B 1979, Norway, pp 456-458

Kumpula J, Colpaert A, Nieminen M (1999) Suomen poronhoitoalueen kesälaidunvarat [The summer pasture resources of the Finnish reindeer management area]. Kala- ja riistaraportteja (Fish and Game Reports), 152. Riistan ja kalantutkimus (Finnish Game and Fish Research Institute), Kaamanen (In Finnish with English abstract)

Kutz SJ, Hoberg EP, Nagy J, Polley L, Elkin B (2004) "Emerging" parasitic infections in Arctic ungulates. Integrative and Comparative Biology 44:109-118. doi:10.1093/icb/44.2.109

Kutz SJ, Hoberg EP, Polley L, Jenkins EJ (2005) Global warming is changing the dynamics of Arctic host-parasite systems. Proceedings Biological Sciences/The Royal Society 272:2571-2576. doi:10.1098/rspb.2005.3285

Kutz SJ, Dobson AP, Hoberg EP (2009) Where are the parasites? Science 326:1187-1188

Kutz SJ, Jenkins EJ, Veitch AM, Ducrocq J, Polley L, Elkin B, Lair $S$ (2009) The Arctic as a model for anticipating, preventing, and mitigating climate change impacts on host-parasite interactions. Veterinary Parasitology 163:217-228

Laaksonen S, Kuusela J, Nikander S, Nylund M, Oksanen A (2007) Outbreak of parasitic peritonitis in reindeer in Finland. The Veterinary Record 160:835-841

Laaksonen S, Solismaa M, Orro T, Saari S, Kortet R, Oksanen A, et al. (2008a) Setaria tundra microfilariae in reindeer and other cervids in Finland. Parasitology Research 104:257-265. doi: 10.1007/s00436-008-1184-0

Laaksonen S, Oksanen A, Orro T, Norberg H, Nieminen M, Sukura S (2008b) Efficacy of different treatment regimes against setariasis (Setaria tundra, Nematoda: Filarioidea) and associated peritonitis in reindeer. Acta Veterinaria Scandinavica 50:49

Laaksonen S, Solismaa M, Kortet R, Kuusela J, Oksanen A (2009) Vectors and transmission dynamics for Setaria tundra (Filarioidea; Onchocercidae), a parasite of reindeer in Finland.
Parasites \& Vectors 2: 3 (DOI: 10.1186/1756-3305-2-3. [online January 6, 2009])

Lafferty KD (2009) The ecology of climate change and infectious diseases. Ecology 90:888-900

Lemke P, et al. (2007) The physical science basis. Contribution of Working Group I to the fourth assessment report of the Intergovernmental Panel on Climate Change. In: Climate Change 2007, Solomon S (editor), , et al.Cambridge: Cambridge University Press, pp 337-383

Löwenberg-Neto P, Navarro-Silva MA (2004) Development, longevity, gonotrophic cycle and oviposition of Aedes albopictus Skuse (Diptera: Culicidae) under cyclic temperatures. Neotropical Entomology 33:29-33

Mörchel FM, Klein DR (1997) Effects of weather and parasitic insects on behaviour and group dynamics of the Delta Herd, Alaska. Canadian Journal of Zoology 75:1659-1670

Nikander S, Laaksonen S, Saari S, Oksanen A (2007) The morphology of the filarioid nematode Setaria tundra, the cause of peritonitis in reindeer Rangifer tarandus. Journal of Helminthology 81:49-55

Nygren T (1990) Hirvikannan tila ja hirvitutkimusten vaihe Lapissa. Riistantutkimusosaston tiedote [Bulletin of Finnish Game and Fisheries Institute] 104:3-21

Patz JA, Epstein PR, Burke TA, Balbus JM (1996) Global climate change and emerging infectious diseases. The Journal of the American Medical Association 275:217-223

Patz JA, Graczyk TK, Gellera N, Vittorc AY (2000) Effects of environmental change on emerging parasitic diseases. International Journal for Parasitology 30:1395-1405. doi:10.1016/S00207519(00)00141-7

Pollard RH, Ballard WB, Noel LE, Cronin MA (1996) Parasitic insect abundance and microclimate of gravel pads and tundra within the Prudhoe Bay oil field, Alaska, in relation to use by Caribou, Rangifer tarandus granti. Canadian Field-Naturalist 110:649-658

Rehbinder C, Christensson D, Glatthard V (1975) Parasitic granulomas in reindeer. A histopathological, parasitological and bacteriological study. Nordisk Veterinae Medicine 27:499-507

Taylor LH, Latham SM, Woolhouse ME (2001) Risk factors for human disease emergence. Philosophical Transactions of the Royal Society of London. Series B: Biological Sciences 356:983989. doi:10.1098/rstb.2001.0888

Tryland M, Godfroid J, Arneberg P (2009) Impact of climate change on infectious diseases of animals in the Norwegian Arctic. Norsk Polarinstitut, Kortrapport/Brief Report Series 10:126

Vors LS, Boyce MS (2009) Global declines of caribou and reindeer. Global Change Biology (DOI:10.1111/j.1365-2486.2009. 01974 [online May 9, 2009])

Weladj RB, Klein DR, Holand Ø, Mysterud A (2002) Comparative response of Rangifer tarandus and other northern ungulates to climatic variability. Rangifer 22:33-50

World Health Organization (2007) Global programme to eliminate lymphatic filariasis: annual report on lymphatic filariasis 2006. Weekly Epidemiological Record 82:361-380

Ytrehus B, Bretten T, Bergsjø B, Isaksen K (2008) Fatal pneumonia epizootic in musk ox (Ovibos moschatus) in a period of extraordinary weather. EcoHealth 5:213-223. doi:10.1007/ s10393-008-0166-0 